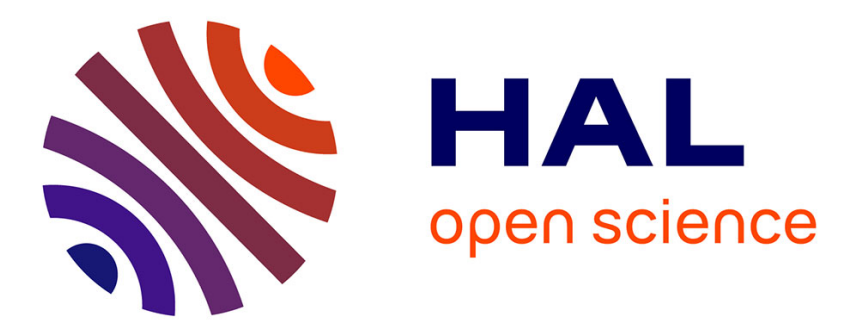

\title{
Delayed ischemia after subarachnoid hemorrhage: result of vasospasm alone or a broader vasculopathy?
}

Daniel Zemke, Muhammad U Farooq, Abutaher Mohammed Yahia, Arshad Majid

\section{- To cite this version:}

Daniel Zemke, Muhammad U Farooq, Abutaher Mohammed Yahia, Arshad Majid. Delayed ischemia after subarachnoid hemorrhage: result of vasospasm alone or a broader vasculopathy?. Vascular Medicine, 2007, 12 (3), pp.243-249. 10.1177/1358863X07081316 . hal-00571363

\section{HAL Id: hal-00571363 https://hal.science/hal-00571363}

Submitted on 1 Mar 2011

HAL is a multi-disciplinary open access archive for the deposit and dissemination of scientific research documents, whether they are published or not. The documents may come from teaching and research institutions in France or abroad, or from public or private research centers.
L'archive ouverte pluridisciplinaire HAL, est destinée au dépôt et à la diffusion de documents scientifiques de niveau recherche, publiés ou non, émanant des établissements d'enseignement et de recherche français ou étrangers, des laboratoires publics ou privés. 


\title{
Delayed ischemia after subarachnoid hemorrhage: result of vasospasm alone or a broader vasculopathy?
}

\author{
Daniel Zemke ${ }^{a}$, Muhammad U Farooq ${ }^{a}$, Abutaher Mohammed Yahia ${ }^{a}$ and Arshad Majid ${ }^{a, b}$
}

\begin{abstract}
The term vasospasm is commonly used to describe constriction of cerebral blood vessels after subarachnoid hemorrhage which results in the restriction of blood flow and ischemia in affected portions of the brain. The pathophysiological changes that underlie vascular constriction after subarachnoid hemorrhage include changes within the vessel walls themselves, alteration of the levels of several vasoactive substances, and broader pathological conditions such as immune responses, inflammation, and oxidative damage. In this review, we summarize the current state of knowledge concerning the processes that occur in cerebral blood vessels after subarachnoid hemorrhage and how they may be involved in the development of vasospasm. We also propose that, rather than merely vasospasm, the multitude of vascular effects occurring after subarachnoid hemorrhage can be best described as a post-subarachnoid hemorrhage vasculopathy.
\end{abstract}

Key words: acute vasospasm; delayed vasospasm; subarachnoid hemorrhage; vasculopathy

\section{Introduction}

Subarachnoid hemorrhage (SAH) affects an estimated 25000 to 30000 individuals in the USA each year, and is a significant source of death and disability. ${ }^{1}$ Nearly $35 \%$ of patients do not survive the initial insult. Subsequent to SAH, many survivors experience constriction of cerebral arteries, commonly described as vasospasm. The exact mechanism by which constriction of cerebral arteries occurs following SAH is unclear, and may involve a number of factors. Arterial constrictions typically occur within 3-21 days after SAH and may last for $12-16$ days. $^{1}$ At 7 days after $\mathrm{SAH}$, angiographic evidence indicating vascular constriction, commonly termed 'arterial vasospasm', is present in approximately $30-70 \%$ of patients. $^{2}$ However, only $20-30 \%$ display signs of neurological deficit, termed 'symptomatic vasospasm'. Constriction of cerebral vessels leads to the restriction of blood flow, causing severe cerebral ischemia in some patients, and is associated with an increase in mortality

\footnotetext{
aDepartment of Neurology and Ophthalmology and bivision of Cerebrovascular Disease and Neurocritical Care, Michigan State University, East Lansing, MI, USA

Address for correspondence: Arshad Majid, A-217 Clinical Center, Michigan State University, East Lansing, MI 48824, USA. Tel: +1 517432 6247; Fax: +1 517432 9414; E-mail: arshad.majid@ht.msu.edu
}

of 1.5-3-fold during the first 2 weeks after SAH. ${ }^{3}$ The term 'cerebral vasospasm' is commonly used to describe both the actual arterial constriction and the symptomatic deficits. The effects of SAH are not limited to vascular constriction, however, and may include damage to vascular tissue caused by inflammation and oxidative stress, indicating the presence of a broader pathologic condition. The purpose of this review is to suggest that these additional aspects should be taken into account during formulation of a treatment strategy in order to maximize benefit and minimize neurological damage following $\mathrm{SAH}$.

\section{Vascular changes after SAH}

Many of the vascular effects of vasospasm have been evaluated using animal models of SAH. Animal models have the benefit of high reproducibility and the ability to evaluate changes at specific time points after $\mathrm{SAH}$, which cannot be achieved with post-mortem human tissue. Models of SAH have been developed in a number of species, including dogs, cats, rats, and even primates. ${ }^{4-9}$ The double-hemorrhage model is most commonly used and typically consists of two injections of autologous blood into the cisterna magna. ${ }^{6}$ A single-hemorrhage model consisting of only one injection of blood may also be used. In rats, an endovascular puncture model involving puncture of the internal carotid artery at its bifurcation point is 
used as well. Other models may involve the implantation of preformed clots into the subarachnoid space, such as in primates. ${ }^{9}$ In a comparison of models used in rats, the double-hemorrhage model was found to best represent the time course of SAH in humans and produce the greatest severity of vasospasm. ${ }^{6}$

Within 3-7 days after SAH in dogs, there is a significant decrease in the internal diameter of arterioles in the brain that is associated with an increase in wall thickness. ${ }^{4}$ Within the tunica media, there is hypertrophy and hyperplasia of smooth muscle cells. There are also signs of cell damage and death such as pallor of the smooth muscle and pale, pyknotic nuclei with indistinct cell membranes. Inflammation secondary to SAH can also lead to an increase in the thickness of the tunica adventitia. Collagen fibers within the cerebral vascular wall are increased after SAH in cats, particularly on the adventitial side..$^{5}$ Connective tissue within the vessels is increased, and there is increased fibrosis in the tunica media, intima, and subintima. Moreover, there are obvious changes in the internal elastic lamina such as corrugations and increased thickness. Increased wall thickness is accompanied by narrowing of the lumen due to fibrotic and fibroproliferative processes. Changes in human vessels are similar to those reported in experimental animal models and include thickening of the tunica adventitia due to edema with associated accumulation of inflammatory cells, necrosis and atrophy of smooth muscle cells in the tunica media, and thickening of the tunica intima due to increased connective tissue and fibrosis leading to a decrease in lumen diameter. ${ }^{6,7}$

The endothelium also exhibits changes in response to SAH. Endothelial cells appear swollen, detached from the basement membrane, and necrotic in a rat model of SAH. ${ }^{8}$ There is a vacuolization in their cytoplasm and nuclei, disruption of tight junctions, and widening of the inter-endothelial space. Endothelial cells show signs of apoptosis beginning at 3 days after SAH in a canine model. ${ }^{9}$ The use of caspase inhibitors to block apoptosis has been shown to reduce angiographic vasospasm in dogs. ${ }^{10}$ There are also changes in the endothelial response to vasoactive agents in the cerebral vessels after SAH. The effects of acetylcholine and the endothelium-dependent vasodilator calcimycin on cerebral blood flow and cerebrovascular resistance are altered after SAH in a primate model. ${ }^{11}$ Endothelial dysfunction as a result of SAHinduced damage may therefore play an important role in the occurrence of vasospasm.

\section{Inflammatory responses to SAH}

During the first hour after SAH, white blood cells (WBCs) begin to associate with the endothelium. ${ }^{12}$ Adhesion of WBCs to the endothelium and their subsequent migration into the periadventitial space may play an important role in vascular constriction. Adhesion of WBCs to the endothelium is mediated by lymphocyte function-associated antigen-1 (CD11a/CD18) and macrophage antigen-1 (CD11b/CD18) on neutrophils and macrophages, and by intercellular adhesion molecule-1 (CD54) on endothelial cells. Monoclonal antibodies directed against CD11/CD18 inhibit the decrease in lumen diameter following $\mathrm{SAH}$ in rabbits. ${ }^{13}$ One potential role for WBCs in the response to SAH may be the secretion of cytokines. Activation of interleukin-1 beta is increased in lipopolysaccharide stimulated monocytes from SAH patients with symptomatic cerebral vasospasm. ${ }^{14}$ Peak leukocyte counts greater than $1.5 \times 10^{10} / 1$ are associated with a greater than threefold increase in vasospasm after SAH. ${ }^{15}$

Phospholipase activity, which involves the release of arachidonic acid and other free fatty acids from membrane phospholipids, is enhanced after many types of brain injury. ${ }^{16}$ The production of inflammatory cytokines after $\mathrm{SAH}$ results in the induction of cyclooxygenase 2 , which is involved in the breakdown of arachidonic acid. ${ }^{17}$ The lipoxygenase pathway of arachidonic acid breakdown is also stimulated by SAH. ${ }^{18}$ The products of these enzymes have roles in vasoconstriction of blood vessels, neutrophil and eosinophil chemotaxis, activation of lymphocytes, increased vascular permeability, and increased reactive oxygen species production. ABT-761 and 1,2bis(nicotinamido)propane, inhibitors of 5-lipoxygenase, attenuate the vasospastic response in experimental animals. ${ }^{19,20}$

Platelet-activating factor (PAF) may also play an important role in the inflammatory response and vasospasm after SAH. Plasma concentrations of PAF are higher in SAH patients with cerebral infarction due to vasospasm. ${ }^{21}$ Animal studies have shown that the administration of the PAF antagonist E5880 can prevent vasospasm following SAH. ${ }^{22}$ Inhibition of poly(ADP-ribose), another important molecule in modulating inflammation, also attenuates cerebral vasospasm. ${ }^{23}$ Inflammation therefore seems to play multiple roles in the development of vasospasm, and presents a number of possible targets for the treatment of SAH.

\section{The influence of molecular mechanisms on vasospasm after SAH}

\section{Nitric oxide, hemoglobin, and endothelin}

The constant release of nitric oxide (NO) from the endothelium helps to maintain basal cerebrovascular tone by inducing vascular relaxation. The release of NO by endothelial cells has been shown to be decreased after SAH. ${ }^{24}$ Nitric oxide is an inhibitor of the vasoconstrictor endothelin-1, and inhibition of NO synthesis leads to vessel constriction and reduced blood flow that can be alleviated by endothelin receptor blockade. ${ }^{25}$ 
Endothelin results in the influx of calcium into vascular smooth muscle cells, leading to their contraction and vessel constriction. Endothelin levels are increased in the cerebrospinal fluid (CSF), plasma, and hypothalamus after $\mathrm{SAH}^{26}$ Increased plasma endothelin is associated with delayed cerebral ischemia and vasospasm after SAH. ${ }^{27}$ Lysis of red blood cells after SAH also leads to the release of hemoglobin, resulting in increased concentrations within the perivascular space. ${ }^{28}$ Hemoglobin binds and inhibits the activity of $\mathrm{NO}$, thereby enhancing vascular constriction.

In rodent models of $\mathrm{SAH}$, intracranial administration of nitric oxide donors increases levels of NO and prevents vasospasm. ${ }^{29}$ The NO donor sodium nitroprusside has also been shown to prevent or even reverse vasospasm when administered intraventricularly in human SAH patients. ${ }^{30}$ Inhibition of endothelin-induced calcium influx reduces the magnitude of vasospasm in animal models of $\mathrm{SAH}^{31}$ Metabolism of hemoglobin by hemoxygenase-1 or chelation of its ferrous component also prevents vasospasm in animals models of SAH. ${ }^{32,33}$ These results suggest that a reduction in NO availability may play a role in the pathogenesis of vasospasm, and that the administration of NO donors may be beneficial for the prevention and treatment of vasospasm. The use of polymers that allow a controlled release of NO donors has shown considerable promise in animal models. ${ }^{29}$ To date, however, only local injection of these polymers directly into the brain has been tested. This route of administration may be a limiting factor in the treatment of human patients due to the specialized facilities that would be required. The effects of these compounds when administered via more traditional routes should be explored to determine whether they are practical and safe for widespread use.

\section{Free radicals and oxidative damage}

Reactive oxygen species, particularly superoxide, are believed to play a role in the pathogenesis of vasospasm after SAH. Effects of superoxide include destruction of NO, DNA and protein dysfunction, lipid peroxidation, and elevation in the levels of hydrogen peroxide. Lipid peroxides in the CSF are increased following $\mathrm{SAH}$ in the dog and can be blocked by the administration of methylprednisolone. ${ }^{34}$ Enhanced production of superoxide is seen in the subarachnoid space after SAH and can be blocked by the intracisternal administration of superoxide dismutase, which metabolizes superoxide into less toxic products, in a canine SAH model. ${ }^{35}$ Mice overexpressing superoxide dismutase also show reduced vasospasm after SAH. ${ }^{36}$

Oxidative damage is believed to play a role in a number of neurological diseases, and a considerable amount of effort is being put into the investigation of antioxidants as potential treatment. It is possible that one of these compounds may prove to be beneficial for the treatment of vasospasm as well. The free radical scavenger tirilazad mesylate, although showing initial signs of promise, has failed in human trials upon further study. Among four large multicenter trials, only one has shown a reduction in the frequency and severity of vasospasm. ${ }^{37-40}$ The differences between trials can potentially be explained by methodological differences, particularly the use of other potentially beneficial treatments. Numerous other potential compounds remain to be tested, however, many of which can be easily administered and have already been shown to be safe for use in humans.

\section{Prevention and treatment of vasospasm}

In some cases, the occurrence of hemorrhage can be avoided with proper treatment. Endovascular coiling, for example, may restrict blood from entering an aneurysm and prevent it from rupturing (Figure 1). Once hemorrhage has occurred, however, efforts should focus on
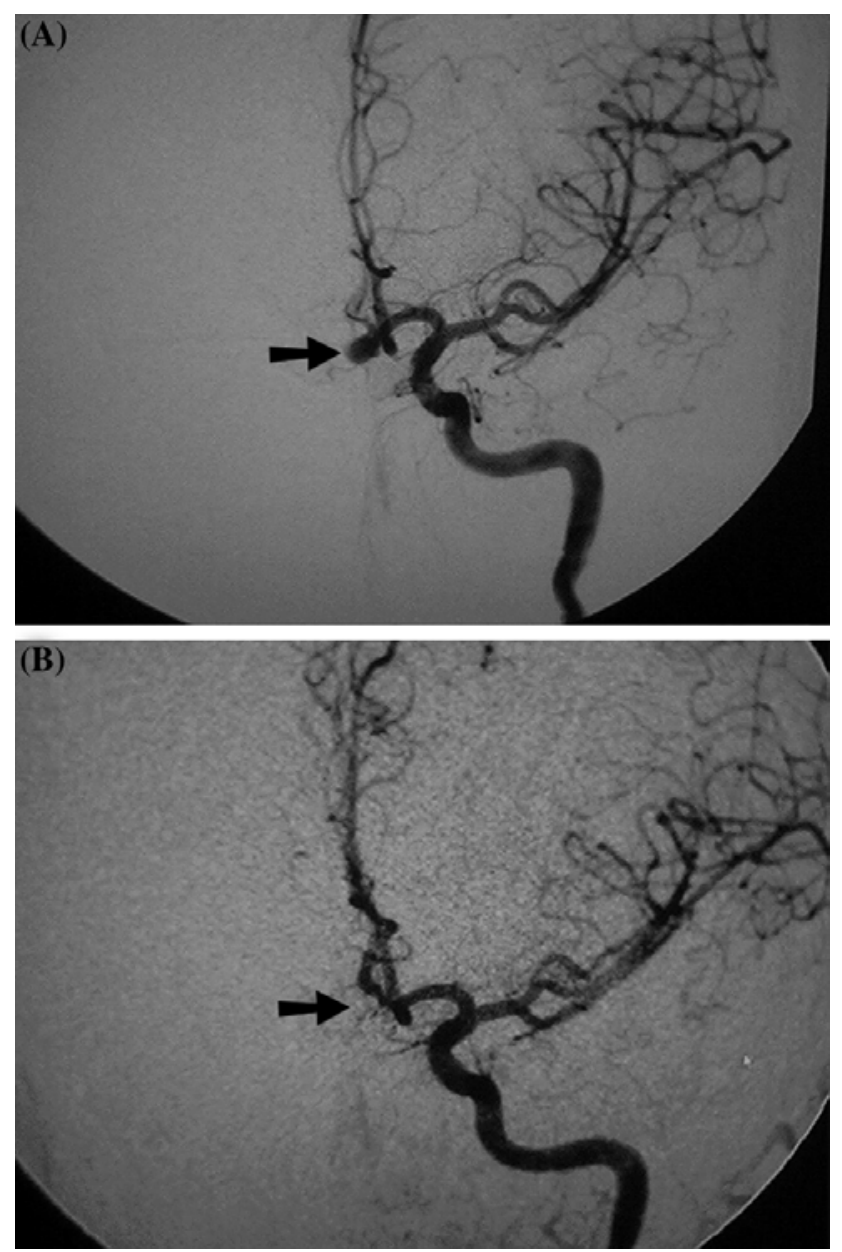

Figure 1 Angiography of the left internal carotid artery in a patient presenting with subarachnoid hemorrhage. An aneurysm of the anterior communicating artery $(A$, arrow) is completely excluded from the circulation after endovascular coiling (B). 
preventing its pathological effects. It is therefore important to predict and detect the occurrence of vasospasm in SAH patients as early as possible in order to maximize the effects of preventative treatment. Clinical grade is commonly used as a predictor for the risk of vasospasm, but other criteria may also be used for the evaluation of patient risk such as the amount of blood in the subarachnoid space, the size and location of the hemorrhage, age, sex, hypertension, and tobacco or drug use. ${ }^{5}$ Currently, however, the presence of a large amount of blood in the subarachnoid space is the only consistent risk factor for vasospasm. Transcranial Doppler ultrasonography can also be effective for the prediction of vasospasm, but only after the vessel has begun to constrict, thus limiting the amount of time for preventative treatment before the onset of ischemia.

The most common form of prevention of vasospasm after SAH is the administration of calcium antagonists such as nimodipine. By preventing the calciuminduced contraction of vascular smooth muscle, nimodipine and other antagonists may be useful to block the occurrence of arterial constriction after $\mathrm{SAH}$. Oral nimodipine treatment has been shown to reduce the incidence of cerebral infarction after subarachnoid hemorrhage. ${ }^{41}$ Intra-arterial nimodipine has also been shown to be beneficial for the treatment of vasospasm. ${ }^{42}$ Among a group of nine patients treated with intra-arterial nimodipine, vessel diameter in the vasospastic segment increased by an average of $66.6 \%$ with no alteration of blood pressure. Intravenous nimodipine, however, appears to have no benefit, and other calcium antagonists have failed to consistently prevent vasospasm when tested. ${ }^{43}$ For example, the calcium channel blocker verapamil, commonly used for the treatment of coronary vasospasm, has shown improvement in some studies but no effect in others. ${ }^{44,45}$ Evaluation of 12 clinical trials with a total of 2844 patients, 1396 of which received calcium antagonists, found an overall risk reduction of $5.1 \%$ with calcium antagonist treatment. ${ }^{43}$ This reduction, however, could be attributed primarily to oral nimodipine treatment, and the results of treatment with nicardipine, AT877, or magnesium were considered inconclusive.

Treatment for vasospasm may include the induction of hypervolemia, hypertension, and hemodilution, commonly known as 'Triple-H therapy'. ${ }^{46}$ The goal of this treatment is to maintain adequate blood flow through affected vessels. Triple- $\mathrm{H}$ therapy has been shown to maintain or improve neurologic grade in a majority of patients, resulting in minor or no neurological deficits. ${ }^{47}$ The efficacy of this treatment has been questioned, however, and in some cases it may be harmful. ${ }^{48}$ Endovascular treatments such as balloon angioplasty or administration of vasodilators or calcium antagonists may also be used to increase the luminal diameter of constricted vessels during vasospasm (Figure 2). Angioplasty has been shown to result in clinical improvement, particularly when administered early after the onset of symptoms. ${ }^{49}$ Other groups, however, have found no improvement in outcome after angioplasty despite effective reversal of vasospasm. ${ }^{50}$ The effectiveness of this procedure, therefore, is questionable. The nonspecific smooth muscle relaxant papaverine can also be used to increase the lumen size in vasospastic vessels, either alone or in combination with angioplasty. ${ }^{51}$

Several other compounds have also shown promise for the treatment of vasospasm. Magnesium sulfate has been shown to reverse vasospasm after $\mathrm{SAH}$ in rats. ${ }^{52}$ Although further studies are needed, it has also been shown to reduce the occurrence of delayed cerebral ischemia after SAH in human trials. ${ }^{53}$ Out of 283 patients receiving either magnesium or placebo, magnesium reduced the risk of new lesion development by $34 \%$. Potential mechanisms of magnesium
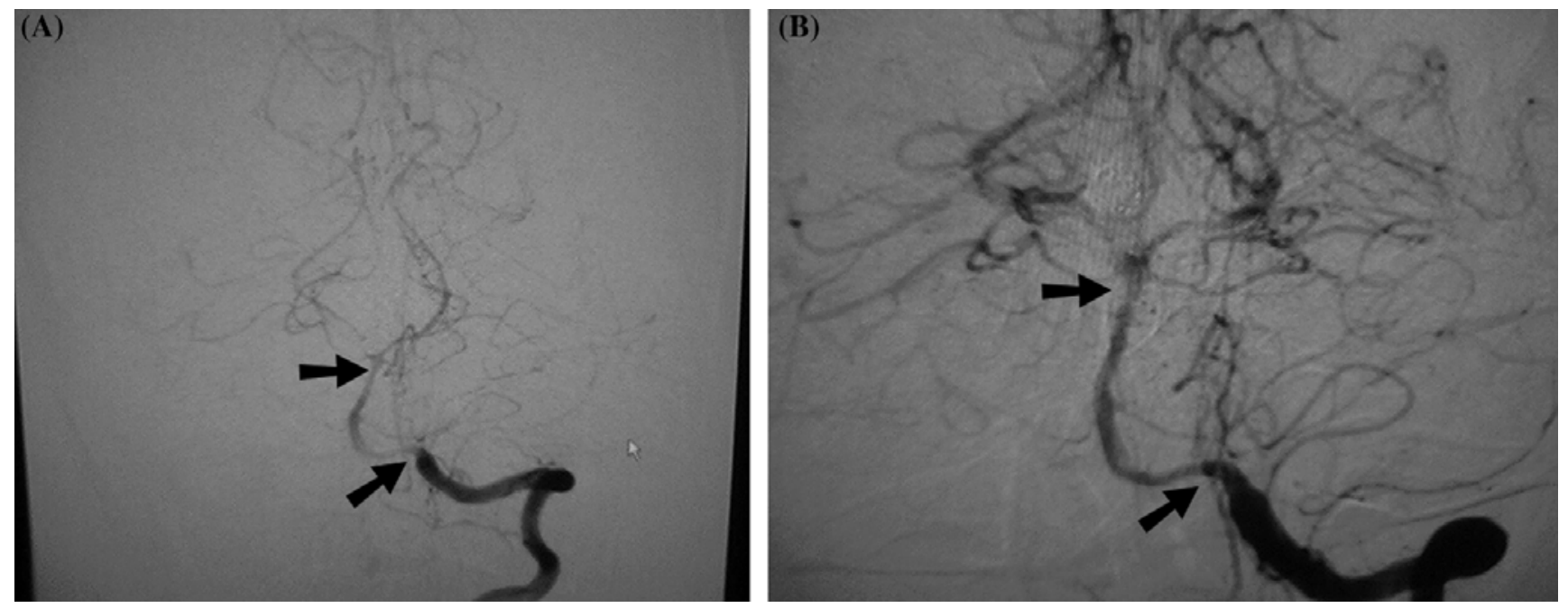

Figure 2 Angiography of the left vertebral and basilar artery showing vasospasm before treatment ( $\mathrm{A}$, arrows) and improvement after intra-arterial verapamil (B). 
include inhibition of excitatory amino acid release and antagonism of NMDA receptors and calcium channels. ${ }^{54}$ Statins, or 3-hydroxy-3-methylglutaryl coenzyme A reductase (HMGR) inhibitors, may represent another potential treatment. In addition to their known role in blocking cholesterol synthesis, statins also regulate nitric oxide levels and have antioxidant and antiinflammatory properties. ${ }^{55}$ Pravastatin has been shown to reduce the incidence and duration of vasospasm after SAH in clinical trials. ${ }^{56}$ Among a group of 80 patients given pravastatin or placebo, pravastatin treatment reduced the incidence of vasospasm by $32 \%$ and shortened the duration by 0.8 days. More importantly, delayed ischemic deficits were reduced by $83 \%$ and mortality by $75 \%$. Studies with a larger number of patients are currently in progress.

The American Heart Association has established guidelines for the management of subarachnoid hemorrhage. ${ }^{57}$ However, these guidelines were formulated in 1994, and before endovascular therapy was commonly used. These guidelines include recommendations for the treatment of vasospasm. The recommended treatment is clipping of the aneurysm, Triple-H therapy for the management of ischemic complications, and oral nimodipine for the improvement of outcome. Patients should be closely monitored during treatment, and transluminal angioplasty is recommended if the standard treatment fails. Although a number of promising treatments are currently under evaluation, further study is still needed to determine their safety and efficacy compared with what is currently being used.

\section{Summary}

The exact mechanism by which vasospasm is induced following $\mathrm{SAH}$ is unknown. One potential pathway emphasizing the roles of nitric oxide and endothelin is shown in Figure 3. In this pathway, the level of NO is decreased by a number of factors, leading to an increase in endothelin levels that induces calcium influx and vascular constriction. This is but one potential mechanism for the induction of vasospasm, and it is likely that many other pathways are involved. Further research is required to determine which pathways, if any, play a dominant role. From the studies described above, it is clear that vasospasm can be influenced by a number of factors. What is not clear, however, is the magnitude of the role that each of these factors plays in the development of vasospasm after $\mathrm{SAH}$. It is possible that only one or a few of these processes are directly responsible for the induction of vasospasm and that the remainders serve only to modulate the degree of vascular constriction. Furthermore, many of these processes have other effects on tissue that are unrelated to their potential role in vasospasm. Endothelial cell death within blood vessels would be expected to have additional effects beyond constriction of blood vessels. Inflammation and reactive oxygen

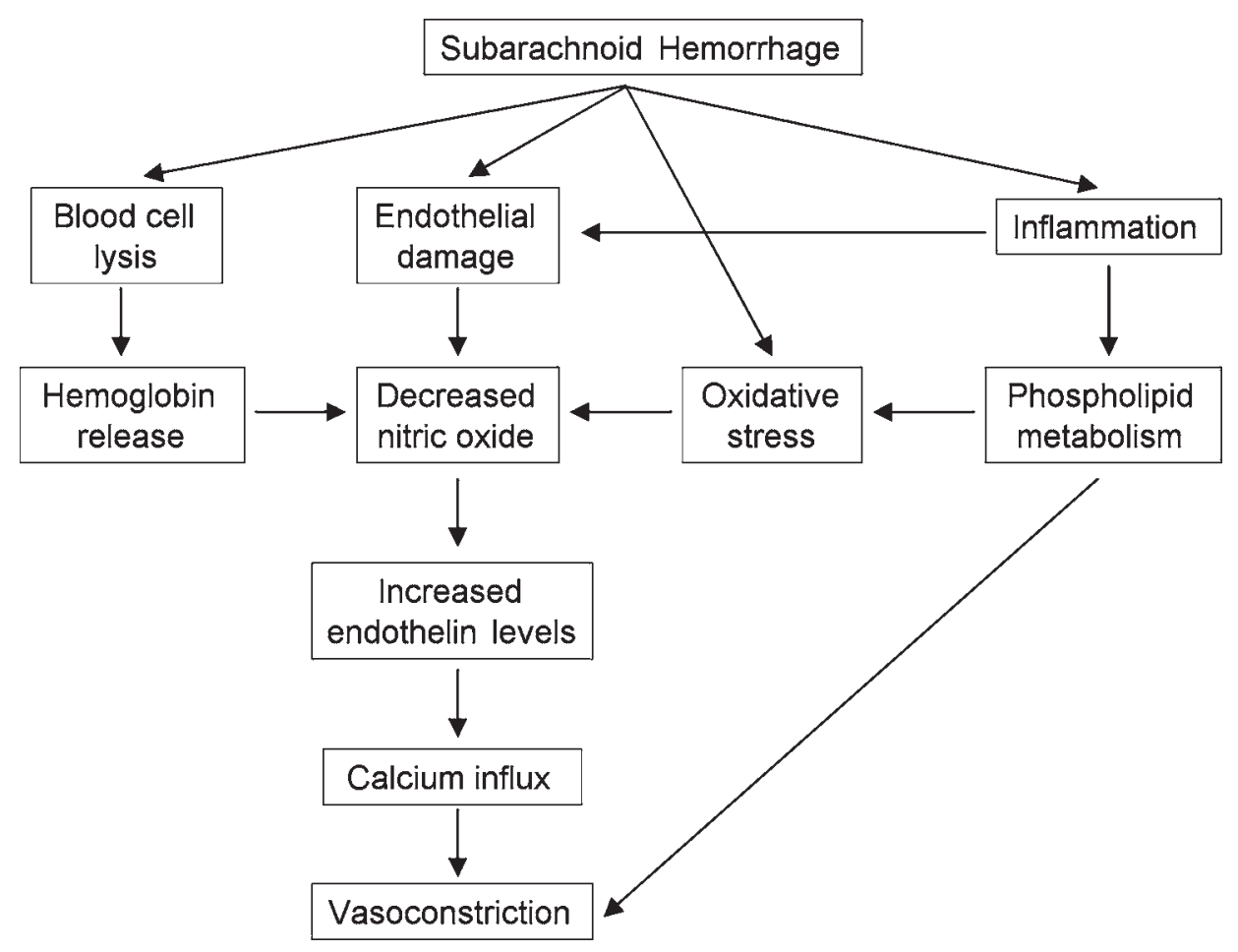

Figure 3 Potential role of nitric oxide in the induction of vasospasm. 
species are expected to be damaging not only to vessels but to the surrounding tissue. In addition, many of the molecules and enzymes mentioned in this review function in multiple biochemical pathways. Vasospasm may therefore be considered as merely one component of a broader condition involving multiple damaging effects. The term vasospasm specifically refers to only a single phenomenon, the constriction of blood vessels, and is therefore inadequate to encompass the full range of effects seen. We therefore propose the use of a broader term, postsubarachnoid hemorrhage vasculopathy, to better describe the resulting condition after SAH.

\section{References}

1 Oyama K, Criddle L. Vasospasm after aneurysmal subarachnoid hemorrhage. Crit Care Nurse 2004; 24: 58-67.

2 Harrod CG, Bendok BR, Batjer HH. Prediction of cerebral vasospasm in patients presenting with aneurysmal subarachnoid hemorrhage: a review. Neurosurgery 2005; 56: 633-54.

3 Treggiari-Venzi MM, Suter PM, Romand JA. Review of medical prevention of vasospasm after aneurysmal subarachnoid hemorrhage: a problem of neurointensive care. Neurosurgery 2001; 48: 249-61.

4 Ohkuma H, Itoh K, Shibata S, Suzuki S. Morphological changes of intraparenchymal arterioles after experimental subarachnoid hemorrhage in dogs. Neurosurgery 1997; 41: 230-35.

5 Nakamura S, Tsubokawa T, Yoshida K, Hirasawa T, Nakano M. Appearance of collagen fibers in the cerebral vascular wall following subarachnoid hemorrhage. Neurol Med Chir (Tokyo) 1992; 32: 877-82.

6 Conway LW, McDonald LW. Structural changes of the intradural arteries following subarachnoid hemorrhage. J Neurosurg 1972; 37: 715-23.

7 Hughes JT, Schianchi PM. Cerebral artery spasm. A histological study at necropsy of the blood vessels in cases of subarachnoid hemorrhage. J Neurosurg 1978; 48: 515-25.

8 Gules I, Satoh M, Clower BR, Nanda A, Zhang JH. Comparison of three rat models of cerebral vasospasm. Am $J$ Physiol Heart Circ Physiol 2002; 283: H2551-59.

9 Zubkov AY, Tibbs RE, Clower B, Ogihara K, Aoki K, Zhang $\mathrm{JH}$. Morphological changes of cerebral arteries in a canine double hemorrhage model. Neurosci Lett 2002; 326: 137-41.

10 Zhou C, Yamaguchi M, Kusaka G, Schonholz C, Nanda A, Zhang JH. Caspase inhibitors prevent endothelial apoptosis and cerebral vasospasm in dog model of experimental subarachnoid hemorrhage. J Cereb Blood Flow Metab 2004; 24 : 419-31.

11 Iuliano BA, Pluta RM, Jung C, Oldfield EH. Endothelial dysfunction in a primate model of cerebral vasospasm. J Neurosurg 2004; 100: 287-94.

12 Alkan T, Tureyen K, Ulutas M et al. Acute and delayed vasoconstriction after subarachnoid hemorrhage: local cerebral blood flow, histopathology, and morphology in the rat basilar artery. Arch Physiol Biochem 2001; 109: 145-53.

13 Pradilla G, Wang PP, Legnani FG, Ogata L, Dietsch GN, Tamargo RJ. Prevention of vasospasm by anti-CD11/CD18 monoclonal antibody therapy following subarachnoid hemorrhage in rabbits. J Neurosurg 2004; 101: 88-92.
14 Nam DH, Kim JS, Hong SC et al. Expression of interleukin-1 beta in lipopolysaccharide stimulated monocytes derived from patients with aneurysmal subarachnoid hemorrhage is correlated with cerebral vasospasm. Neurosci Lett 2001; 312: 41-44.

15 McGirt MJ, Mavropoulos JC, McGirt LY et al. Leukocytosis as an independent risk factor for cerebral vasospasm following aneurysmal subarachnoid hemorrhage. J Neurosurg 2003; 98: 1222-26.

16 Phillis JW, O'Regan MH. The role of phospholipases, cyclooxygenases, and lipoxygenases in cerebral ischemic/traumatic injuries. Crit Rev Neurobiol 2003; 15: 61-90.

17 Osuka K, Suzuki Y, Watanabe Y, Takayasu M, Yoshida J. Inducible cyclooxygenase expression in canine basilar artery after experimental subarachnoid hemorrhage. Stroke 1998; 29: 1219-22.

18 Shimizu T, Watanabe T, Asano T, Seyama Y, Takakura K. Activation of the arachidonate 5-lipoxygenase pathway in the canine basilar artery after experimental subarachnoidal hemorrhage. J Neurochem 1988; 51: 1126-31.

19 Barbosa MD, Arthur AS, Louis RH et al. The novel 5-lipoxygenase inhibitor ABT-761 attenuates cerebral vasospasm in a rabbit model of subarachnoid hemorrhage. Neurosurgery 2001; 49: 1205-12.

20 Watanabe T, Asano T, Shimizu T, Seyama Y, Takakura K. Participation of lipoxygenase products from arachidonic acid in the pathogenesis of cerebral vasospasm. J Neurochem 1988; 50: $1145-50$.

21 Hirashima Y, Endo S, Kurimoto M, Tsukamoto E, Takaku A. Platelet-activating factor and antiphospholipid antibodies in subarachnoid haemorrhage. Acta Neurochir (Wien) 1994; 128: 144-49.

22 Hirashima Y, Endo S, Kato R, Takaku A. Prevention of cerebrovasospasm following subarachnoid hemorrhage in rabbits by the platelet-activating factor antagonist, E5880. J Neurosurg 1996; 84: 826-30.

23 Satoh M, Date I, Nakajima M et al. Inhibition of poly(ADPribose) polymerase attenuates cerebral vasospasm after subarachnoid hemorrhage in rabbits. Stroke 2001; 32: 225-31.

24 Hongo K, Kassell NF, Nakagomi T et al. Subarachnoid hemorrhage inhibition of endothelium-derived relaxing factor in rabbit basilar artery. J Neurosurg 1988; 69: 247-53.

25 Cardillo C, Kilcoyne CM, Cannon RO 3rd, Panza JA. Interactions between nitric oxide and endothelin in the regulation of vascular tone of human resistance vessels in vivo. Hypertension 2000; 35: 1237-41.

26 Wang X, Zhu C, Zhang G, Lu Y. Changes of endothelin during cerebral vasospasm after experimental subarachnoid hemorrhage. Chin Med J (Engl) 1995; 108: 586-90.

27 Juvela S. Plasma endothelin concentrations after aneurysmal subarachnoid hemorrhage. J Neurosurg 2000; 92: 390-400.

28 Pluta RM, Afshar JK, Boock RJ, Oldfield EH. Temporal changes in perivascular concentrations of oxyhemoglobin, deoxyhemoglobin, and methemoglobin after subarachnoid hemorrhage. J Neurosurg 1998; 88: 557-61.

29 Gabikian P, Clatterbuck RE, Eberhart CG, Tyler BM, Tierney TS, Tamargo RJ. Prevention of experimental cerebral vasospasm by intracranial delivery of a nitric oxide donor from a controlledrelease polymer: toxicity and efficacy studies in rabbits and rats. Stroke 2002; 33: 2681-86.

30 Thomas JE, Rosenwasser RH. Reversal of severe cerebral vasospasm in three patients after aneurismal subarachnoid hemorrhage: initial observations regarding the use of intraventricular sodium nitroprusside in humans. Neurosurgery 1999; 44: 48-57. 
31 Kawanabe Y, Masaki T, Hashimoto N. Effects of the Ca++permeable nonselective cation channel blocker LOE 908 on subarachnoid hemorrhage-induced vasospasm in the basilar artery in rabbits. $J$ Neurosurg 2003; 98: 561-64.

32 Ono S, Komuro T, Macdonald RL. Heme oxygenase-1 gene therapy for prevention of vasospasm in rats. J Neurosurg 2002; 96: 1094-102.

33 Horky LL, Pluta RM, Boock RJ, Oldfield EH. Role of ferrous iron chelator 2,2'-dipyridyl in preventing delayed vasospasm in a primate model of subarachnoid hemorrhage. J Neurosurg 1998; 88: 298-303.

34 Shibata S, Suzuki S, Ohkuma H, Kimura M, Fujita S. Effects of intracisternal methylprednisolone on lipid peroxidation in experimental subarachnoid haemorrhage. Acta Neurochir (Wien) 1999; 141: 529-32.

35 Mori $\mathrm{T}$, Nagata K, Town T, Tan J, Matsui T, Asano T. Intracisternal increase of superoxide anion production in a canine subarachnoid hemorrhage model. Stroke 2001; 32: 636-42.

36 Kamii H, Kato I, Kinouchi H et al. Amelioration of vasospasm after subarachnoid hemorrhage in transgenic mice overexpressing CuZn-superoxide dismutase. Stroke 1999; 30: 867-71.

37 Kassell NF, Haley EC Jr, Apperson-Hansen C, Alves WM. Randomized, double-blind, vehicle-controlled trial of tirilazad mesylate in patients with aneurysmal subarachnoid hemorrhage: a cooperative study in Europe, Australia, and New Zealand. J Neurosurg 1996; 84: 221-28.

38 Haley EC Jr, Kassell NF, Apperson-Hansen C, Maile MH, Alves WM. A randomized, double-blind, vehicle-controlled trial of tirilazad mesylate in patients with aneurysmal subarachnoid hemorrhage: a cooperative study in North America. J Neurosurg 1997; 86: 467-74.

39 Lanzino G, Kassell NF, Dorsch NW et al. Double-blind, randomized, vehicle-controlled study of high-dose tirilazad mesylate in women with aneurysmal subarachnoid hemorrhage. Part I. A cooperative study in Europe, Australia, New Zealand, and South Africa. J Neurosurg 1999; 90: 1011-17.

40 Lanzino G, Kassell NF. Double-blind, randomized, vehiclecontrolled study of high-dose tirilazad mesylate in women with aneurysmal subarachnoid hemorrhage. Part II. A cooperative study in North America. J Neurosurg 1999; 90: 1018-24.

41 Pickard JD, Murray GD, Illingworth R et al. Effect of oral nimodipine on cerebral infarction and outcome after subarachnoid haemorrhage: British aneurysm nimodipine trial. $B M J$ 1989; 298: 636-42.

42 Hui C, Lau KP. Efficacy of intra-arterial nimodipine in the treatment of cerebral vasospasm complicating subarachnoid haemorrhage. Clin Radiol 2005; 60: 1030-36.

43 Rinkel GJ, Feigin VL, Algra A, van den Bergh WM, Vermeulen M, van Gijn J. Calcium antagonists for aneurysmal subarachnoid haemorrhage. Cochrane Database Syst Rev 2005; 1: CD000277.

44 Feng L, Fitzsimmons BF, Young WL et al. Intraarterially administered verapamil as adjunct therapy for cerebral vasospasm: safety and 2-year experience. AJNR Am J Neuroradiol 2002; 23: 1284-90.

45 Mazumdar A, Rivet DJ, Derdeyn CP, Cross DT 3rd, Moran CJ. Effect of intraarterial verapamil on the diameter of vasospastic intracranial arteries in patients with cerebral vasospasm. Neurosurg Focus 2006; 21: E15.

46 Wilson SR, Hirsch NP, Appleby I. Management of subarachnoid haemorrhage in a non-neurosurgical centre. Anaesthesia 2005; 60: 470-85.

47 Awad IA, Carter LP, Spetzler RF, Medina M, Williams FC Jr. Clinical vasospasm after subarachnoid hemorrhage: response to hypervolemic hemodilution and arterial hypertension. Stroke 1987; 18: 365-72.

48 Lee KH, Lukovits T, Friedman JA. 'Triple-H' therapy for cerebral vasospasm following subarachnoid hemorrhage. Neurocrit Care 2006; 4: 68-76.

49 Bejjani GK, Bank WO, Olan WJ, Sekhar LN. The efficacy and safety of angioplasty for cerebral vasospasm after subarachnoid hemorrhage. Neurosurgery 1998; 42: 979-86.

50 Polin RS, Coenen VA, Hansen CA et al. Efficacy of transluminal angioplasty for the management of symptomatic cerebral vasospasm following aneurysmal subarachnoid hemorrhage. J Neurosurg 2000; 92: 284-90.

51 Liu JK, Couldwell WT. Intra-arterial papaverine infusions for the treatment of cerebral vasospasm induced by aneurysmal subarachnoid hemorrhage. Neurocrit Care 2005; 2: 124-32.

52 Ram Z, Sadeh M, Shacked I, Sahar A, Hadani M. Magnesium sulfate reverses experimental delayed cerebral vasospasm after subarachnoid hemorrhage in rats. Stroke 1991; 22: 922-27.

53 Van den Bergh WM, Algra A, van Kooten F et al. Magnesium sulfate in aneurysmal subarachnoid hemorrhage: a randomized controlled trial. Stroke 2005; 36: 1011-15.

54 Van den Bergh WM, Dijkhuizen RM, Rinkel GJ. Potentials of magnesium treatment in subarachnoid haemorrhage. Magnes Res 2004; 17: 301-13.

55 Vaughan CJ, Delanty N. Neuroprotective properties of statins in cerebral ischemia and stroke. Stroke 1999; 30: 1969-73.

56 Tseng MY, Czosnyka M, Richards H, Pickard JD, Kirkpatrick PJ. Effects of acute treatment with pravastatin on cerebral vasospasm, autoregulation, and delayed ischemic deficits after aneurysmal subarachnoid hemorrhage: a phase II randomized placebo-controlled trial. Stroke 2005; 36: 1627-32.

57 Mayberg MR, Batjer HH, Dacey R et al. Guidelines for the management of aneurysmal subarachnoid hemorrhage. A statement for healthcare professionals from a special writing group of the Stroke Council, American Heart Association. Stroke 1994; 25: 2315-28. 